Postprint: Janssen H. 2016. A discussion of "Analysis of the water absorption test to assess the intrinsic permeability of earther materials", Construction and Building Materials, 215: 1044-1046.

doi: 10.1016/j.ijheatmasstransfer.2016.03.031

\title{
A DISCUSSION OF "ANALYSIS OF THE WATER ABSORPTION TEST TO ASSESS THE INTRINSIC PERMEABILITY OF EARTHEN MATERIALS"
}

\author{
HANS JANSSEN ${ }^{a, *}$
}

a: KU Leuven, Department of Civil Engineering, Building Physics Section

*: corresponding author, Kasteelpark Arenberg 40, 3001 Leuven, Belgium; hans.janssen@kuleuven.be; +32 16321326

\begin{abstract}
In February 2019, this journal published the article "Analysis of the water absorption test to assess the intrinsic permeability of earthen materials". The author of this discussion considers the article's simplification of moisture transfer in porous materials to a "competition between the kinetics of water ingress within the wall, which is driven by intrinsic permeability, and water evaporation, which is rather driven by resistance to vapour diffusion at the wall surfaces" in contradiction with the state-of-the-art on this topic. It is therefore reiterated that decades of research demonstrate the intrinsically unsaturated nature of moisture transfer in porous materials. The discussion continues by reviewing the article's application of Kiessl's/Künzel's exponential diffusivity. Whereas the article observes that this exponential diffusivity overestimates the capillary absorption, the theory on this formulation states that it should correctly reproduce the capillary absorption. It is furthermore noted that a similar application of the exponential diffusivity by one of the article's authors in a related work contrarily results in an underestimation of the capillary absorption. These contradictions can only be explained by the faulty application of the exponential diffusivity by the article's authors, rather than the exponential diffusivity being unsuited for earthen materials, as currently concluded in the article.
\end{abstract}

\section{KEYWORDS}

Unsaturated moisture transfer; intrinsic moisture permeability; exponential diffusivity; earthen materials

\section{HIGHLIGHTS}

- A recent article oversimplifies the basics of moisture transfer in porous materials

- The article also comes to flawed results with the exponential diffusivity approach

- This discussion restates moisture transfer's fundamentally unsaturated character

- And shows that the exponential diffusivity must reproduce the capillary absorption 
Postprint: Janssen H. 2016. A discussion of "Analysis of the water absorption test to assess the intrinsic permeability of earther materials", Construction and Building Materials, 215: 1044-1046.

doi: 10.1016/j.ijheatmasstransfer.2016.03.031

\section{INTRODUCTION}

In February 2019, this journal published the article "Analysis of the water absorption test to assess the intrinsic permeability of earthen materials" [1], wherein a relation between the intrinsic permeability and the capillary absorption coefficient of these materials is proposed and validated. This pursuit is based on the premise that this intrinsic permeability governs the "kinetics of the water ingress within the wall". Its experimental determination is somewhat complex though, and therefore its indirect determination via the more easily measurable capillary absorption coefficient is investigated.

In the opinion of this discussion's author however, this simplification of the moisture response of porous materials reverses decades of research on unsaturated moisture transfer in soil science [2] and building physics [3]. The fact that the moisture response of porous materials is primarily based on unsaturated moisture storage and transport is well established and large amounts of research have been dedicated to characterising moisture storage and transport properties over the entire saturation range. The concepts engrained in the disputed article appear to negate that state-of-the-art and this discussion aims at coming to its defence.

The intrinsically unsaturated nature of moisture transfer implies that complete moisture storage and transport functions are to be determined. In the past Kiessl [4] and Künzel [5] have brought an exponential diffusivity approach, only requiring the capillary absorption coefficient and capillary moisture content. The application of Kiessl's/Künzel's exponential diffusivity in [1] is unsuccessful however, and it is judged to be "not suitable" "to estimate accurately the water diffusion coefficient from the A-value" for earthen materials. It will be shown below that this conclusion is contradicted by the theory on this front, and that it hence cannot be correct.

In what follows, first the wider perspective is considered, focusing on the prevalence of unsaturated conditions in moisture transfer in porous materials. Particular attention is paid to the issue of rising damp, which appears to be a central concern in the framework of [1]. The need for the saturation-dependent moisture diffusivity or permeability is made clear. That then leads to the central discussion of the unsuccessful application of Kiessl's/Kunzel's exponential diffusivity in [1], which is shown to be in contradiction with theory. It is conclusively advocated that applying an exponential moisture diffusivity outclasses employing a constant intrinsic permeability.

\section{WIDER PERSPECTIVE}

In [1], the moisture response of porous materials is boiled down to "the competition between the kinetics of water ingress within the wall, which is driven by intrinsic permeability, and water evaporation, which is rather driven by resistance to vapour diffusion at the wall surfaces". With respect to rising damp in particular, it is extrapolated that "there is no need to know the variation of permeability with water content to assess the rising damp phenomenon, which would considerably simplify its modelling".

This simplification of moisture transport in porous materials to liquid transport at capillary saturation refutes the state-of-the-art in the field on moisture transfer in porous materials. While such simplification may hold for the capillary absorption experiment, it is not valid for most other moisture transfer regimes. It is well established that the absorption of wind-driven rain typically does not yield saturated conditions [6], and that the second drying phase is dominated by the internal unsaturated moisture transport [7]. These two illustrations overturn [1]'s conjectures on "water ingress" "driven by intrinsic permeability" and "water evaporation" "driven by resistance to vapour diffusion at the wall surfaces".

In relation to rising damp in particular, there is also evidence that the issue should not be simplified to a "moisture front penetration problem". Simulations of moisture saturation distributions in rising damp configurations are performed and presented in [8,9]. Figures 2 and 3 in [8] and 12 and 13 in [9] show that these moisture distributions do not reveal a sharp moisture front (a sharp separation between the wet and dry zone in the material), instead a gradually declining moisture saturation is obtained. These two examples invalidate [1]'s assumption that "there is no need to know the variation of permeability with water content", given the clear spectrum of moisture con- 
Postprint: Janssen H. 2016. A discussion of "Analysis of the water absorption test to assess the intrinsic permeability of earther materials", Construction and Building Materials, 215: 1044-1046.

doi: 10.1016/j.ijheatmasstransfer.2016.03.031

tents and hence moisture permeabilities. No publications with respect to rising damp are referenced in [1] though.

\section{MoISTURE DIFFUSIVITY}

The arguments above annul [1]'s concept that the intrinsic permeability is the sole moisture transport property to be characterised for assessments of the moisture responses of porous materials. Instead hence, the variation of the transport property - moisture permeability or diffusivity, when respectively using capillary pressure or moisture content as potential - must be accounted for, and the full transport property curve must be determined. Most often, this full transport property curve is determined by visualised moisture content profiles during capillary absorption [10]. After Boltzmann-transforming these moisture content profiles into the so-called lambda profile, the moisture diffusivity (for a large part of the moisture saturation range) can be obtained. When desired, this can be translated into moisture permeability, with use of the moisture storage property of the material.

Admittedly, the required equipment and necessary processing does not make this a straightforward option [11]. Alternatively, one can opt for less demanding but approximating methods, like the exponential diffusivity estimation of Kiessl/Künzel [4-5], or a visual-observation-based technique [12], both based on simple capillary absorption experiments. Kiessl's/Künzel's exponential diffusivity is indeed evaluated in [1], but it is observed that it leads to an overestimation of the capillary absorption speed with about a factor 2, see [1]'s figure 9. And while it is argued below that this is strange given the underlying theories, it is even stranger that a similar application of the exponential diffusivity by one of [1]'s authors in [13] gives an underestimation of the capillary absorption speed, with roughly a factor 10, see [13]'s figure 8.8. It is reasoned below that these internal and external contradictions point toward an erroneous application in [1] and [13].

As an aside, it must be mentioned here that [1]'s derivation and validation of a constant diffusivity, see their equation 15 and figure 9, is respectively ill-suited and circular. While such constant diffusivity replicates the capillary absorption coefficient, its smooth moisture content profiles [14] deviate strongly from the sharp moisture fronts seen in reality. Moreover, validating this method by showing that the constant diffusivity fitted to the capillary absorption coefficient indeed reproduces this same capillary absorption coefficient is merely proof of a correct fitting, not of the approach in general. As second side note, it must be stated here as well that [13]'s linear relation between moisture content and moisture permeability is similarly debatable. It permits mimicking the capillary absorption coefficient but not the moisture content profiles. Neither approach can therefore be valid for general moisture transfer in usually unsaturated conditions.

The focus here however is [1]'s inability to reproduce the capillary absorption coefficient with the exponential diffusivity approach of [4-5], as this contradicts the theory on this issue [15-16]. The latter articles establish a solid link between the exponential diffusivity and the capillary absorption coefficient and capillary moisture content, for an exponential relationship between moisture diffusivity $D\left[\mathrm{~m}^{2} / \mathrm{s}\right]$ and moisture content $\mathrm{w}\left[\mathrm{kg} / \mathrm{m}^{3}\right]$ :

$$
\mathrm{D}(\mathrm{w})=\mathrm{D}_{0} \exp \left(\mathrm{n} \frac{\mathrm{w}}{\mathrm{w}_{\mathrm{cap}}}\right)
$$

with $\mathrm{w}_{\text {cap }}\left[\mathrm{kg} / \mathrm{m}^{3}\right]$ the capillary moisture content and $\mathrm{D}_{0}\left[\mathrm{~m}^{2} / \mathrm{s}\right]$ and $\mathrm{n}[-]$ two shape parameters. If such relationship is assumed, $D_{0}$ can be calculated via [15-16], establishing the mentioned link:

$$
\mathrm{D}_{0}=\left(\frac{\mathrm{A}_{\text {cap }}}{\mathrm{w}_{\text {cap }}}\right)^{2} /\left(\left(\frac{2}{\mathrm{n}}-\frac{1}{\mathrm{n}^{2}}\right) \exp (\mathrm{n})-\frac{1}{\mathrm{n}}+\frac{1}{\mathrm{n}^{2}}\right)
$$

with $A_{\text {cap }}\left[\mathrm{kg} / \mathrm{m}^{2} \mathrm{~s}^{0.5}\right]$ the capillary absorption coefficient. The diffusivity formula of [4-5] reads:

$$
\mathrm{D}(\mathrm{w})=3.8\left(\frac{\mathrm{A}_{\text {cap }}}{\mathrm{w}_{\text {cap }}}\right)^{2} 1000^{\left(\frac{\mathrm{w}}{\mathrm{w}_{\text {cap }}}-1\right)}
$$

which can be translated into the format of equation (1):

$$
\mathrm{D}(\mathrm{w})=\frac{3.8}{1000}\left(\frac{\mathrm{A}_{\text {cap }}}{\mathrm{w}_{\text {cap }}}\right)^{2} \exp \left(\ln (1000) \frac{\mathrm{w}}{\mathrm{w}_{\text {cap }}}\right)=0.0038\left(\frac{\mathrm{A}_{\text {cap }}}{\mathrm{w}_{\text {cap }}}\right)^{2} \exp \left(6.91 \frac{\mathrm{w}}{\mathrm{w}_{\text {cap }}}\right)
$$

This implies that [4-5] assume the shape parameters $n$ and $D_{0}$ of equation (1) equal to: 
Postprint: Janssen H. 2016. A discussion of "Analysis of the water absorption test to assess the intrinsic permeability of earther materials", Construction and Building Materials, 215: 1044-1046.

$$
\mathrm{n}=6.91 \& \mathrm{D}_{0}=0.0038\left(\frac{\mathrm{A}_{\mathrm{cap}}}{\mathrm{w}_{\mathrm{cap}}}\right)^{2}
$$

doi: 10.1016/j.ijheatmasstransfer.2016.03.031

With that value for $n$, equation (2) results in:

$$
\mathrm{D}_{0}=0.0037\left(\frac{\mathrm{A}_{\mathrm{cap}}}{\mathrm{w}_{\mathrm{cap}}}\right)^{2}
$$

This implies that the [4-5]'s formulation complies with equations (1-2), apart from a minor deviation in the constant. This equivalency infers that implementation of the diffusivity formulation of [4-5] should correctly reproduce the capillary absorption coefficient, independent of the choice of the capillary moisture content. Regrettably, such accurate replication is not observed in [1]'s figure 9 nor [13]'s figure 8.8, where, respectively, an overestimation with a factor 2 and an underestimation with a factor 10 are obtained. Given the internal contradiction between [1] and [13], and their external contradiction with [15-16], it can only be concluded that this stems from flawed application in [1] and [13], instead of equation (3) being "not suitable" "to estimate accurately the water diffusion coefficient from the A-value" for earthen materials.

This being said, the message of this discussion is not to be read as explicit support for the accuracy and dependability of the exponential diffusivity approximation of [4-5]. While it certainly has value, its assumed exponential relation and fixed $n$ value remain a generalisation, and may jeopardize its material-specific reliability. In that respect, [12] is expected to lead to more materialspecific and hence more accurate and dependable outcomes. But, in comparison to the methodologies suggested in [1], calculations with such exponential moisture diffusivity always outclass calculations based on a constant intrinsic permeability, as only the former approach features the commonly unsaturated character of moisture transfer in porous materials.

\section{CONCLUSION}

This discussion of the recently published article "Analysis of the water absorption test to assess the intrinsic permeability of earthen materials" [1] argues that the suggested simplification of the moisture response in porous materials to the intrinsic permeability as material property and the surface vapour diffusion resistance as boundary property contradicts decades of research in this field. This discussion instead confirms that the variation of the moisture transport property with moisture content should be accounted for.

That variation can, as first approximation, be considered via the exponential diffusivity approach of Kiessl/Künzel [4-5]. Strangely though, an evaluation of this approach in [1] and [13] is unsuccessful, with an over- and underestimation of the capillary absorption in [1] and [13] respectively. This discussion establishes that the exponential diffusivity formulation of [4-5] indeed complies with the relevant theories on this matter [15-16], implying that it should correctly reproduce the capillary absorption coefficient.

The authors of $[1,13]$ are hence invited to revisit their simulations based on the exponential diffusivity, as well as to adopt the generally accepted stance that moisture transfer in porous materials typically transpires at unsaturated conditions, hence requiring the characterisation of the variation of the moisture storage and transport properties with moisture content. The approaches currently put forward in $[1,13]$ will, in the opinion of this discussion's author, not contribute to the required "good prediction of the water behaviour within earthen walls".

\section{ACKNOWLEDGEMENTS}

Gratitude goes towards the editors of this journal, for the swift and smooth handling of this discussion; regrettably there are scientific journals that strongly obstruct all discussion of published work.

\section{REFERENCES}

1. Fabbri A, Soudani L, McGregor F, Morel J-C, 2019. Analysis of the water absorption test to assess the intrinsic permeability of earthen materials. Construction and Building Materials 199:154-162. 
Postprint: Janssen H. 2016. A discussion of "Analysis of the water absorption test to assess the intrinsic permeability of earther materials", Construction and Building Materials, 215: 1044-1046.

doi: 10.1016/j.ijheatmasstransfer.2016.03.031

2. De Vries DA, 1958. Simultaneous transfer of heat and moisture in porous media. Transactions of the American Geophysical Union 39:909-916.

3. Hall C, 1977. Water movement in porous building materials - I. Unsaturated flow theory and its applications. Building and Environment 12:117-125.

4. KiessI K, 1983. Kapillarer und dampfförmiger Feuchtetransport in mehrschichtigen Bauteilen. Rechnerische Erfassung und bauphysikalische Anwendung (Moisture transfer via liquid and vapour in multi-layered building components). Doctoral dissertation, Universität Gesamthochschule Essen, Essen, Germany.

5. Kunzel HM, 1995. Simultaneous heat and moisture transport in building components: oneand two-dimensional calculation using simple parameters. Fraunhofer IRB Verlag Stuttgart.

6. Janssen H, Blocken B, Roels S, Carmeliet J, 2014. Wind-driven rain as a boundary condition for HAM simulations: Analysis of simplified modelling approaches. Building and Environment 42:1555-1567.

7. Scheffler GA, Plagge R, 2010. A whole range hygric material model: Modelling liquid and vapour transport properties in porous media. International Journal of Heat and Mass Transfer, 53:286-296.

8. Holm A, Künzel HM, 2000. Two-dimensional transient heat and moisture simulations of rising damp with Wufi 2D. In Proceedings of the $12^{\text {th }}$ International Brick/Block Masonry Conference, June 2000, Madrid, Spain.

9. Torres I, de Freitas VP, 2010. The influence of the thickness of the walls and their properties on the treatment of rising damp in historic buildings. Construction and Building Materials, 24:1331-1339.

10. Roels S, Carmeliet J, 2006. Analysis of moisture flow in porous materials using microfocus X-ray radiography. International Journal of Heat and Mass Transfer 49:4762-4772.

11. Roels S, Hens H, Adan O, Brocken H, Pavlik Z, Ellis AT, Hall C, Kumaran K, Pel L, Plagge R. 2004. A comparison of different techniques to quantify moisture content profiles in porous building materials. Journal of Thermal Envelope and Building Science 27:261-276.

12. Evangelides C, Arampatzis G, Tsambali A-A, Tzanetaki E, Tzimopoulos C, 2018. Moisture estimation in building materials with a simple procedure. Construction and Building Materials 164:830-836.

13. Soudani L, 2017. Modelling and experimental validation of the hygrothermal performances of earth as a building material. Doctoral dissertation, Ecole Nationale des Travaux Publics de l'Etat, Vaulx-en-Velin, France.

14. Crank J, 1956. The mathematics of diffusion. Oxford University Press, London, United Kingdom.

15. Lockington D, Parlange JY, Dux P, 1999. Sorptivity and the estimation of water penetration into unsaturated concrete. Materials and Structures 32:342-347.

16. Chunsheng Zhou, 2014. General solution of hydraulic diffusivity from sorptivity test. Cement and Concrete Research 58:152-160. 